\title{
Electrochemical Determination of Sudan Dyes and Two Manner to Realize it: a Theoretical Investigation
}

Volodymyr V. Tkach 1,2,*iD, Marta V. Kushnir ${ }^{1}{ }^{(D)}$, Sílvio C. de Oliveira ${ }^{2}{ }^{\mathbb{D}}$, Yana G. Ivanushko ${ }^{3}$ (D) , Alla V. Velyka ${ }^{3(D)}$, Anzhelika F. Molodianu ${ }^{3}$ (D), Petro I. Yagodynets ${ }^{1}{ }^{(D)}$, Zholt O. Kormosh ${ }^{4 *}{ }^{(D)}$ Lucinda Vaz

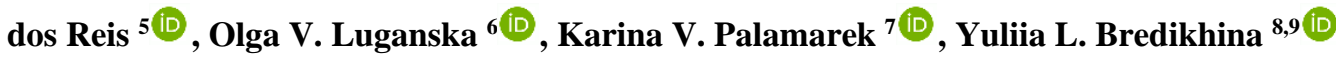

1 Chernivtsi National University, 58000, Kotsyubyns'ky Str. 2, Chernivtsi, Ukraine; nightwatcher2401@gmail.com (V.V.T), vvt2401@chnu.edu.ua (V.V.T.), marta.v.kushnir@gmail.com (M.V.K), ved1988mid@ rambler.ru (P.I.Y)

2 Universidade Federal de Mato Grosso do Sul, Av. Sen. Felinto. Müller, 1555, C/P. 549, 79074-460, Campo Grande, MS, Brazil; scolive@gmail.com (S.C.O)

3 Bukovinian State Medical University, 58001, Teatralna Sq., 9, Chernivtsi Ukraine; yana_iv@ukr.net (Y.G.I), alla.velyka@gmail.com (A.V.V), molodianu.anzhelika@bsmu.edu.ua (A.F.M)

4 Eastern European National University, 43000, Voli Ave., 13, Lutsk, Ukraine; zholt-1971@ukr.net (Z.O.K), kormosh@eenu.edu.ua (Z.O.K)

5 Universidade de Trás-os-Montes e Alto Douro, Quinta de Prados, 5001-801, Folhadela, Vila Real, Portugal; lucinda.reis@utad.pt (L.V.R)

6 Zaporizhzhia National University, 69600, Zhukovsky Str. 66, Zaporizhzhia, Ukraine; 130805olga@ gmail.com (O.V.L)

7 Chernivtsi Institute of Trade and Economics of KNTEU, 58000, Central Sq, 9, Chernivtsi, Ukraine; karinkap55@gmail.com (K.V.P)

8 Melitopol State Pedagogical University, 72300, Melitopol, Hetmanska Str., 20, Ukraine; cvetochek.jul@ ukr.net (Y.L.P)

9 Khortytska Natsionalna Navchalno-Reabilitatsiyna Akademiya, 69000, Naukove Mistechko, 59, Khortytsia Island, Zaporizhzhia, Ukraine

* Correspondence: nightwatcher2401@gmail.com;

Received: 20.07.2020; Revised: 10.08.2020; Accepted: 12.08.2020; Published: 15.08.2020

Abstract: In this work, a general theoretical description of the electrochemical determination of Sudan dyes by cathodic and anodic route has been made. Two mathematical models have been developed for each case, being, afterward, analyzed by means of linear stability theory and bifurcation analysis. It has been shown that in both cases, the systems are efficient from the electroanalytical point of view. The possibility for the oscillatory and monotonic instability has also been verified.

Keywords: food safety; concentration measurements; Sudan dyes; electrochemical sensors; cathodic reduction; anodic oxidation; stable steady-state.

(C) 2020 by the authors. This article is an open-access article distributed under the terms and conditions of the Creative Commons Attribution (CC BY) license (https://creativecommons.org/licenses/by/4.0/).

\section{Introduction}

The use of the chemically modified electrodes has turned one of the most modern tools for electroanalysis of pharmaceutical compounds, pesticides, and other biologically active compounds [1-6]. Their main advantages are precision, rapidity, and affinity to the analyte.

On the other hand, the group of Sudan dyes [7-9] is the group of azo dyes, widely used in histological investigations. Moreover, being fat-soluble, they are used to color vax, oils, petrol derivatives, solvents, and polishes in bright colors-red, orange, and yellow [10-13].

In some countries, these dyes are used (mostly illegally) in food production [14-15]. For example, they are used in order to deepen the color of curry and chilly pepper [16-17]. Also, they are used to falsifythespecies[18-19]. 
The most dangerous is that these dyes may present a high toxicity level [20-23], provoking DNA mutations [24]. Moreover, they are classified as carcinogenic compounds [25], the reason why their use in food is banned in 32 countries [26]. Therefore, the development of a rapid and efficient method for their quantification is really actual [27-30].

Many electrochemical methods have been developed to quantify Sudan dyes [31 - 40], by either anodic or cathodic manner. Nevertheless, all of those works analyze each Sudan dye separately without analyzing the Sudan dyes as a family.

Also, the development of new electroanalytical methods and their application also depend on the resolution of some problems like:

- the indecision about the mechanism of electrooxidation or electrochemical reduction of Sudan dyes during the electroanalytical process;

- the possibility of the electrochemical instabilities, characteristic for either cathodic or anodic transformation of organic compounds (including the electropolymerization) [41-45];

The resolution of these problems is not possible without the development of a mathematical model capable of describing adequately the system's behavior. Moreover, the modeling lets us compare their behavior with that of the other systems.

Therefore, the general objective of this work is a mechanistic theoretical investigation of the Sudan dyes' behavior during their electrooxidation and electroreduction. Its realization is achieved by the realization of specific goals like:

- the suggestion of the mechanism of the electrooxidation and electroreduction of the Sudan dye family;

- development of the mathematical model, correspondent to the mechanism;

- the analysis of the model and its interpretation in terms of steady-state stability and in electroanalytical terms;

- the comparison of the behavior of this system with the behavior of similar ones [4649].

\section{Materials and Methods}

\subsection{System and its modeling.}

The exact electrooxidation mechanism for Sudan dyes haven't been established yet. Nevertheless, considering the involvement of the equal number of protons and electrons, like also the conjugated nature of the compound, it's possible to suppose the most probable electrooxidation mechanism (with an example of Sudan I) as on the Fig. 1.

The possibility of electropolymerization isn't discarded, being electrooxidation in oligomers inter- and intramolecular. The electropolymerization of Sudan dyes may yield a semiconducting or conducting polydopamine-like polymer. Nevertheless, no Sudan I electropolymerization processes have been described yet.

Thus, in order to describe the electrooxidation of Sudan dyes, we introduce three variables:

$\mathrm{c}$-the Sudan dye concentration in the pre-surface layer;

$\theta$ - the anode Sudan dye surface coverage degree;

$\theta^{*}$ - the Sudan dye oligomer surface coverage degree. 


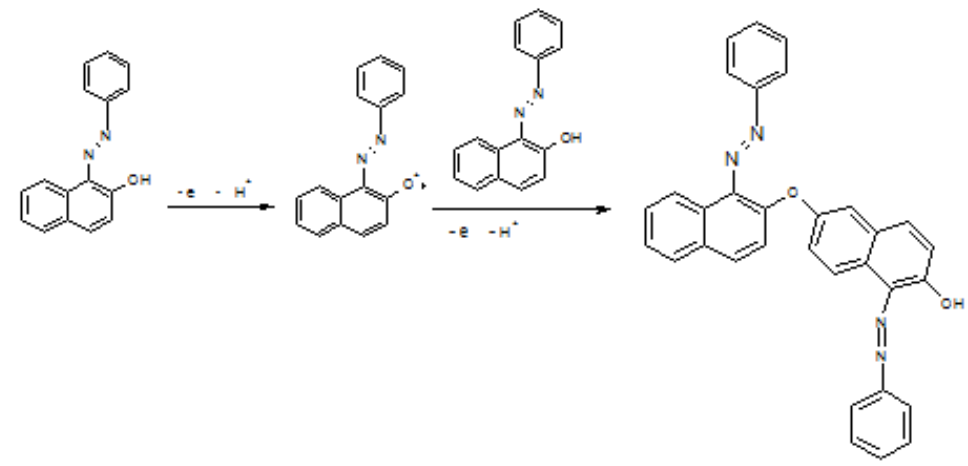

Figure 1. The Sudan dyes electrooxidation.

To simplify the modeling, we suppose that the reactor is intensively stirred, so we can neglect the convection flow. Also, we assume that the background electrolyte is in excess, so we can neglect the migration flow. The diffusion layer is supposed to be of a constant thickness, equal to $\delta$, and the concentration profile in it is supposed to be linear.

It is possible to show that the electroanalytical process will be described by the threedimensional equation set, exposed as:

$$
\left\{\begin{array}{c}
\frac{d c}{d t}=\frac{2}{\delta}\left(\frac{\Delta}{\delta}\left(c_{0}-c\right)+r_{-1}-r_{1}\right) \\
\frac{d \theta}{d t}=\frac{1}{G}\left(r_{1}-r_{-1}-r_{2}\right) \\
\frac{d \theta *}{d t}=\frac{1}{G *}\left(r_{2}-r_{3}\right)
\end{array}\right.
$$

Herein, $\Delta$ is the diffusion coefficient, cois the bulk dye concentration, $G$ is the colorant maximal surface concentration, $\mathrm{G}^{*}$ is the maximal surface concentration of the oligomeric oxidation product, and the parameters $r$ stand for adsorption, desorption, and correspondent reaction rates, calculated as:

$$
\begin{aligned}
& r_{1}=k_{1} c(1-\theta-\theta *) \exp (\alpha \theta) \\
& r_{-1}=k_{-1} \theta \exp (-\alpha \theta) \\
& r_{2}=k_{2} \theta^{m} \exp \left(\frac{n F \varphi}{R T}\right) \\
& r_{3}=k_{2} \theta * \exp \left(\frac{\mu F \varphi}{R T}\right)
\end{aligned}
$$

In which $\mathrm{k}$ are respective reaction rate constants, $\mathrm{n}$ and $\mu$ are the numbers of electrons transferred during the electrochemical processes, $\mathrm{F}$ is the Faraday number, $\mathrm{R}$ is the universal gas constant, and $\mathrm{T}$ is the absolute temperature.

In general terms, this is a system with two consecutive electrochemical reactions, the behavior of which will be described below.

\section{Results and Discussion}

In order to investigate the behavior of the system with the Sudan dyes electrooxidation, we analyze the differential reaction set (1), by means of linear stability theory. The steady-state Jacobian matrix members may be exposed as:

$$
\left(\begin{array}{lll}
a_{11} & a_{12} & a_{13} \\
a_{21} & a_{22} & a_{23} \\
a_{31} & a_{31} & a_{33}
\end{array}\right)
$$

where:

$a_{11}=\frac{2}{\delta}\left(-\frac{\Delta}{\delta}-k_{1}(1-\theta-\theta *) \exp (\alpha \theta)\right)$ 


$$
\begin{aligned}
& a_{12}=\frac{2}{\delta}\left(k_{1} c \exp (\alpha \theta)-\alpha k_{1} c(1-\theta-\theta *) \exp (\alpha \theta)+k_{-1} \exp (-\alpha \theta)-\alpha k_{-1} \theta \exp (-\alpha \theta)\right)(8) \\
& a_{13}=\frac{2}{\delta}\left(k_{1} c \exp (\alpha \theta)\right) \\
& a_{21}=\frac{1}{G}\left(k_{1}(1-\theta-\theta *) \exp (\alpha \theta)\right) \\
& a_{22}=\frac{1}{G}\left(-k_{1} c \exp (\alpha \theta)+\alpha k_{1} c(1-\theta-\theta *) \exp (\alpha \theta)-k_{-1} \exp (-\alpha \theta)+\right. \\
& \left.\alpha k_{-1} \theta \exp (-\alpha \theta)-m k_{2} \theta^{m-1} \exp \left(\frac{n F \varphi}{R T}\right)+j k_{2} \theta^{n} \exp \left(\frac{n F \varphi}{R T}\right)\right) \\
& a_{23}=\frac{1}{G}\left(k_{1} c \exp (\alpha \theta)+p k_{2} \theta^{n} \exp \left(\frac{n F \varphi}{R T}\right)\right) \\
& a_{31}=0 \quad(13) \\
& a_{32}=\frac{1}{G *}\left(m k_{2} \theta^{m-1} \exp \left(\frac{n F \varphi}{R T}\right)-j k_{2} \theta^{n} \exp \left(\frac{n F \varphi}{R T}\right)-j k_{3} \theta^{*} \exp \left(\frac{\mu F \varphi}{R T}\right)\right) \quad(14) \\
& a_{33}=\frac{1}{G}\left(k_{2} \exp \left(\frac{\mu F \varphi}{R T}\right) \quad+p k_{3} \theta * \exp \left(\frac{\mu F \varphi}{R T}\right)-k_{2} \exp \left(\frac{\mu F \varphi}{R T}\right) \quad+p k_{3} \theta * \exp \left(\frac{\mu F \varphi}{R T}\right)\right)
\end{aligned}
$$

Observing the expressions (7), (11) and (15), it is possible to see that the oscillatory behavior, in this case, is possible, as the matrix main diagonal contains the positive elements, describing the positive callback.

These are the elements $\alpha k_{1} c(1-\theta-\theta *) \exp (\alpha \theta)$ and $\alpha k_{-1} \theta \exp (-\alpha \theta)$, describing the attraction between the colorant adsorbed particles, like also the elements $j k_{2} \theta^{n} \exp \left(\frac{n F \varphi}{R T}\right)$, $-p k_{2} \theta^{n} \exp \left(\frac{n F \varphi}{R T}\right)$ and $p k_{2} \theta * \exp \left(\frac{\mu F \varphi}{R T}\right)$, describing the DEL influences on the electrochemical stages. Both of the influences are characteristic for similar systems 49].

In order to investigate the steady-state stability, we apply the Routh-Hurwitz criterion to the differential equation set (1). Avoiding the cumbersome expressions, we introduce the new variables, rewriting the matrix determinant as:

$$
\frac{2}{\delta G G *}\left|\begin{array}{ccc}
-\kappa_{1}-\Xi & \Lambda & P \\
\Xi & -\Lambda-X & -P+\Sigma \\
0 & -X-\Omega & -\Sigma-\Psi
\end{array}\right|
$$

Opening the parenthesis and applying the Det $\mathrm{J}<0$ requisites, salient from the criterion, we obtain the stability condition as:

$$
\left(-\kappa_{1}-\Xi\right)(\Lambda \Sigma+\Lambda \Psi+X \Psi-X P-\Omega P-\Omega \Sigma)+\Xi(-X P-\Omega P+\Lambda \Sigma+\Lambda \Psi)<0
$$

Rearranging the equation (17), expelling the elements with equal modules and opposed signs, we obtain the stability requisite, expressed as:

$$
\left(-\kappa_{1}\right)(\Lambda \Sigma+\Lambda \Psi+X \Psi-X P-\Omega P-\Omega \Sigma)-\Xi(X \Psi-\Omega \Sigma)<0
$$

Easily satisfied, if $X, \Omega, \Sigma$ and $\Psi$ have values correspondent to the DEL influences fragility, and the parameter $\Lambda$, the values, correspondent to the adsorbed particle repulsion. Therefore, the equation on the left side of the inequity (18) will have more negative values, and, consequently, will be satisfied. Itisalsocharacteristical for similar systems [46 - 49].

From the electroanalytical point of view, the steady-state stability is correspondent to the linear dependence between the concentration and the electrochemical parameter. The electroanalytical process will be diffusion-controlled.

The monotonic instability, correspondent to the detection limit from the electroanalytical point of view, is also possible for this system, and its condition will be described as:

$$
\left(-\kappa_{1}\right)(\Lambda \Sigma+\Lambda \Psi+X \Psi-X P-\Omega P-\Omega \Sigma)-\Xi(X \Psi-\Omega \Sigma)=0
$$


In the case of the presence of autocatalytic processes (for example, the autocatalytic chain growth), the expressions, describing the respective process rates, will be modified. Moreover, the autocatalytic influences will be one more factor, responsible for the oscillatory behavior.

\subsection{Cathodic Sudan Dye determination.}

In the case of the cathodic detection, the electroanalytical process will be realized in acidic media and, depending on the solution acidity, will lead to the appearance of a hydrazocompound and, furtherly, of correspondence aromatic amines, as on the Fig. 2.

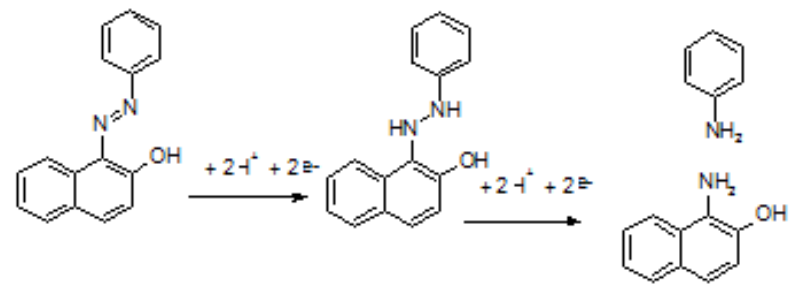

Figure 2. The cathodic Sudan dyes determination.

In this case, the system's behavior will be similar to that observed for benzodiazepines, described in [49]. Therefore, it will be described briefly in this system.

As in [49], the system will include the so-called "hydrogen evolution" and will be described by a tridimensional differential equation system, as:

$$
\left\{\begin{array}{c}
\frac{d \varepsilon}{d t}=\frac{2}{\delta}\left(\frac{\Delta}{\delta}\left(\varepsilon_{0}-\varepsilon\right)+\rho_{-1}-\rho_{1}\right) \\
\frac{d \eta}{d t}=\frac{1}{\psi}\left(\rho_{1}-\rho_{-1}-\rho_{2}\right) \\
\frac{d h}{d t}=\frac{2}{\delta}\left(\frac{d}{\delta}\left(h_{0}-h\right)-\rho_{2}-\rho_{3}\right)
\end{array}\right.
$$

Analyzing the differential equation set (20), it will be a possible conclusion that:

- The steady-state stability in this system is maintained in the case of the repulsion of the adsorbed particles and of the fragility of the electrochemical influences in DEL. The reaction process will be controlled by the diffusion of both dye and protons.

- The topological zone of the electroanalytical efficiency of the steady-state stability will be less vast than of the general stability conditions, due to the "hydrogen evolution". Nevertheless, in order to augment the electroanalytical efficiency, moderately acidic solutions have to be used. Another alternative is the use of the electrode materials, impeding the hydrogen evolution.

- The oscillatory behavior in this system is caused by surface and electrochemical factors, but it is less probable than in the case of anodic oxidation. The augment o $\mathrm{pH}$ will augment the wavelength but will decrease the oscillation frequency.

Therefore, among the anodic and cathodic reactions, it is preferable to use the cathodic reduction, as it is more sensitive and exact for the determination of Sudan dyes.

\section{Conclusions}

The behavior analysis of the system with Sudan dyes electrochemical oxidation and reduction, realized for electroanalytical purposes, let us conclude that in both of the cases, we deal with efficient diffusion-controlled electroanalytical systems. The stability of the steadystate, corresponding to the linear dependence between the current and dye concentration, is safeguarded by the adsorbed particle repulsion, and DEL influences fragility. The opposite factors are responsible for the oscillatory and monotonic instability. Also, the cathodic process, 
if realized on the materials impeding the hydrogen evolution, is realized by a more efficient manner than the anodic electrochemical determination.

\section{Funding}

This research received no external funding.

\section{Acknowledgments}

This research has no acknowledgment.

\section{Conflicts of Interest}

The authors declare no conflict of interest.

\section{References}

1. Kumar, Y.; Vashistha, V.K.; Das, D.K., Synthesis of Perovskite-type $\mathrm{NdFeO}_{3}$ nanoparticles and used as electrochemical sensor for detection of paracetamol. Lett. Appl. Nanobiosci. 2020, 9, 866-869, https://doi.org/10.33263/LIANBS91.866869.

2. Long, X. Electrochemical Sensors with Antifouling Properties for Sensitive Detection of Isoproturon Based on Glassy Carbon Electrode Modified with Nafion Membrane. International Journal of Electrochemical Science 2020, 15, 4964-4977, https://doi.org/10.20964/2020.06.58.

3. Sant'Anna, M.V.S.; Carvalho, S.W.M.M.; Gevaerd, A.; Silva, J.O.S.; Santos, E.; Carregosa, I.S.C.; Wisniewski, A.; Marcolino-Junior, L.H.; Bergamini, M.F.; Sussuchi, E.M. Electrochemical sensor based on biochar and reduced graphene oxide nanocomposite for carbendazim determination. Talanta 2020, 220, https://doi.org/10.1016/j.talanta.2020.121334.

4. Laghrib, F.; Bakasse, M.; Lahrich, S.; El Mhammedi, M.A. Electrochemical sensors for improved detection of paraquat in food samples: A review. Materials Science and Engineering: C 2020, 107, https://doi.org/10.1016/j.msec.2019.110349.

5. Pérez-Fernández, B.; Costa-García, A.; Muñiz, A.D. Electrochemical (Bio)Sensors for Pesticides Detection Using Screen-Printed Electrodes. Biosensors 2020, 10, https://doi.org/10.3390/bios10040032.

6. Xiang, H.; Cai, Q.; Li, Y.; Zhang, Z.; Cao, L.; Li, K.; Yang, H. Sensors Applied for the Detection of Pesticides and Heavy Metals in Freshwaters. Journal of Sensors 2020, 2020, https://doi.org/10.1155/2020/8503491.

7. Arregui, M.; Fernández, A.; Paz-Sánchez, Y.; Santana, Á.; Sacchini, S.; Sierra, E.; Arbelo, M.; de Quirós, Y.B. Comparison of Three Histological Techniques for Fat Emboli Detection in Lung Cetacean's Tissue. Scientific Reports 2020, 10, https://doi.org/10.1038/s41598-020-64821-8

8. Pyon, W; Gray, D.T.; Barnes, C. An Alternative to Dye-Based Approaches to Remove Background Autofluorescence From Primate Brain Tissue. Front Neuroanat. 2019, 13, https://doi.org/10.3389/fnana.2019.00073.

9. Lochocki, B.; Morrema, T.H.J.; Ariese, F.; Hoozemans, J.J.M.; de Boer, J.F. The search for a unique Raman signature of amyloid-beta plaques in human brain tissue from Alzheimer's disease patients. Analyst 2020, 145, 1724-1736, https://doi.org/10.1039/C9AN02087J.

10. Lellis, B.; Fávaro-Polonio, C.Z.; Pamphile, J.A.; Polonio, J.C. Effects of Textile Dyes on Health and the Environment and Bioremediation Potential of Living Organisms. Biotechn. Res. Inn. 2019, 3, 275-290, https://doi.org/10.1016/j.biori.2019.09.001.

11. Benkhaya, S.; Mrabet, S.; El Harfi, A. Classifications, Properties and Recent Synthesis and Applications of Azo Dyes. Heliyon 2020, 6, https://doi.org/10.1016/j.heliyon.2020.e03271.

12. Zin, K.M.; Effendi Halmi, M.I.; Abd Gani, S.S.; Zaidan, U.H.; Samsuri, A.W.; Abd Shukor, M.Y. Microbial Decolorization of Triazo Dye, Direct Blue 71: An Optimization Approach Using Response Surface Methodology (RSM) and Artificial Neural Network (ANN). BioMed Research International 2020, 2020, https://doi.org/10.1155/2020/2734135

13. Ishchi, T.; Sibi, G. Azo Dye Degradation by Chlorella vulgaris: Optimization and Kinetics. International Journal of Biological Chemistry 2020, 14, 1-7, https://doi.org/10.3923/ijbc.2020.1.7

14. Iammarino, M.; Mentana, A.; Centonze, D.; Palermo, C.; Mangiacotti, M.; Chiaravalle, A.E. Dye use in fresh meat preparations and meat products: a survey by a validated method based on HPLC-UV-diode array detection as a contribution to risk assessment. International Journal of Food Science \& Technology 2020, 55, 1126-1135, https://doi.org/10.1111/ijfs.14275. 
15. Clofent, D.; de Homdedeu, M.; Muñoz-Esquerre, M.; Cruz, M.J.; Muñoz, X. Sudan red dye: a new agent causing type-2 occupational asthma. Allergy, Asthma \& Clinical Immunology 2020, 16, https://doi.org/10.1186/s13223-020-0404-8.

16. Andoh, S.S.; Nyave, K.; Asamoah, B.; Kanyathare, B.; Nuutinen, T.; Mingle, C.; Peiponen, K.-E.; Roussey, M. Optical screening for presence of banned Sudan III and Sudan IV dyes in edible palm oils. Food Additives \& Contaminants: Part A 2020, 37, 1049-1060, https://doi.org/10.1080/19440049.2020.1726500.

17. Homaeigohar, S. The Nanosized Dye Adsorbents for Water Treatment. Nanomaterials 2020, 10, https://doi.org/10.3390/nano10020295.

18. Reza, M.S.A.; Hasan, M.M.; Kamruzzaman, M.; Hossain, M.I.; Zubair, M.A.; Bari, L.; Abedin, M.Z.; Reza, M.A.; Khalid-Bin-Ferdaus, K.M.; Haque, K.M.F.; Islam, K.; Ahmed, M.U.; Hossain, M.K. Study of a common azo food dye in mice model: Toxicity reports and its relation to carcinogenicity. Food Science \& Nutrition 2019, 7, 667-677.

19. Sebaei, A.S.; Youssif, M.I.; Ghazi, A.A.M. Determination of Seven Illegal Dyes in Egyptian Species by HPLC with Gel Permeation Chromatography Clean-Up. J. Food Comp. Anal. 2019, 84, https://doi.org/10.1016/j.jfca.2019.103304

20. Dubenska, L.; Tvorynska, S. Synthetic Food Dyes - Some Aspects Of Use And Methods Of Determination. Methods and Objects of Chemical Analysis 2020, 15, 5-20, https://doi.org/10.17721/moca.2020.5-20

21. Cox, J.A; White, P.A. The Mutagenic Activity of Select Azo Compounds in MutaMouse Target Tissues in vivo and Primary Hepacytes in vitro. Mut. Res. Gen. Tox. Env. Mut. 2019, 844, 25-34, https://doi.org/10.1016/j.mrgentox.2019.06.003.

22. Yang, Y.; Zhang, J.; Yin, J.; Yang, Y. Fast Simultaneous Determination of Eight Sudan Dyes in Chili Oil by Ultra-High-Performance Supercritical Fluid Chromatography. Journal of analytical methods in chemistry 2019, 2019, https://doi.org/10.1155/2019/3731028.

23. Andoh, S.S.; Nuutinen, T.; Mingle, C.; Roussey, M. Qualitative analysis of Sudan IV in edible palm oil. Journal of the European Optical Society-Rapid Publications 2019, 15, https://doi.org/10.1186/s41476-0190117-0.

24. Karomi, A.S.A. Identification of Some Potential Mutagens in IZO Colorants Using Bacterial Model, Ann. Trop. Med. Publ. Health, 2020, 23, https://doi.org/10.36295/ASRO.2020.231036.

25. Gandhi, M.; Mashru, R. Detection of Adulterants in Red Chilli Powder with Special Emphasis on Qualitative and Quantitative Estimation of Sudan I Dye in Red Chilli Powder. Int. J. Res Rev. 2019, 6, 107-112.

26. Zhou, Q.; Wu, Y; Sheng, X. Determination of Sudan Red Contaminants at Trace Level from Water Samples by Magnetic Solid-Phase Extraction Using Fe@NiAl-Layered Double Hydroxide, Coupled with HPLC. Env. Sci. Europe 2019, 31, https://doi.org/10.1186/s12302-019-0215-z.

27. Çağılcı, O.C.; Gümrükçüoğlu, A.; Alp, H.; Vanlı, E.; Ocak, Ü.; Ocak, M.J.K.C.S.; Technology. Baharatlarda Sudan I boyası'nın tayini için basit bir spektroflorimetrik yöntem. Karadeniz Chem. Sci. Techn. 2017, 1, 1621.

28. Al Tamim, A.; AlRabeh, M.; Al Tamimi, A.; AlAjlan, A.; Alowaifeer, A. Fast and simple method for the detection and quantification of 15 synthetic dyes in sauce, cotton candy, and pickle by liquid chromatography/tandem mass spectrometry. Arabian Journal of Chemistry 2020, 13, 3882-3888, https://doi.org/10.1016/j.arabjc.2019.09.008

29. Ntrallou, K.; Gika, H.; Tsochatzis, E. Analytical and Sample Preparation Techniques for the Determination of Food Colorants in Food Matrices. Foods 2020, 9, https://doi.org/10.3390/foods9010058.

30. Sivrikaya Ozak, S.; Y1lmaz, Y. Ultrasound-assisted hydrophobic deep eutectic solvent based solid-liquid microextraction of Sudan dyes in spice samples. Spectrochimica Acta Part A: Molecular and Biomolecular Spectroscopy 2020, 236, https://doi.org/10.1016/j.saa.2020.118353.

31. Tajik, S.; Beitollahi, H.; Nejad, F.G.; Safaei, M.; Mohammadzadeh Jahani, P. Electrochemical sensing of Sudan I using the modified graphite screen-printed electrode. International Journal of Environmental Analytical Chemistry 2020, 100, 1-14, https://doi.org/10.1080/03067319.2020.1738418.

32. Konrad, P.; Marta, P.; Małgorzata, O. Electrochemical reduction of azo dyes mimicking their biotransformation to more toxic products. Journal of Veterinary Research 2019, 63, 433-438, https://doi.org/10.2478/jvetres-2019-0044.

33. Afanga, H.; Zazou, H.; Titchou, F.E.; Rakhila, Y.; Akbour, R.A.; Elmchaouri, A.; Ghanbaja, J.; Hamdani, M. Integrated electrochemical processes for textile industry wastewater treatment: system performances and sludge settling characteristics. Sustainable Environment Research 2020, 30, https://doi.org/10.1186/s42834019-0043-2.

34. Vinothkumar, V.; Sangili, A.; Chen, S.M. Voltammetric Determination of Sudan I by Using $\mathrm{Bi}_{2} \mathrm{WO}_{6}$ Nanosheets Modified Glassy Carbon Electrode. Int. J. Electrochem. Sci. 2020, 15, 2414-2429, https://doi.org/10.20964/2020.03.08.

35. Heydari, M.; Ghoreishi, S.M.; Khoobi, A. Novel Electrochemical Procedure for Sensitive Determination of Sudan II Based on Nanostructured Modified Electrode and Multivariate Optimization. Measurement 2020, 142, 105-112, https://doi.org/10.1016/j.measurement.2019.04.058.

36. Karaboduk, K.; Erdoğan, H. Voltammetric Determination of Sudan I in Food Samples Using Its Cu (II) Compound. Food Techn. Biotechn. 2018, 56, 573-580, https://doi.org/10.17113/ftb.56.04.18.5679. 
37. Tajik, S.; Aflatoonian, M.R.; Shabanzade, R.; Beitollahi, H.; Alizadeh, R. Amplified electrochemical sensor employing $\mathrm{ZnO}-\mathrm{CuO}$ nanoplates for sensitive analysis of Sudan I. International Journal of Environmental Analytical Chemistry 2020, 100, 109-120, https://doi.org/10.1080/03067319.2019.1631304

38. Shah, A. A Novel Electrochemical Nanosensor for the Simultaneous Sensing of Two Toxic Food Dyes. ACS Omega 2020, 5, 6187-6193, https://doi.org/10.1021/acsomega.0c00354.

39. Zeng, L., Peng, L.; Wu, D.; Yang, B. Electrochemical Sensors for Food Safety. In: Nutrition in Health and Disease - Our Challenges Now and Forthcoming Times 2018, https://doi.org/10.5772/intechopen.82501

40. Nezhad, H.M.; Shahidi, S.A.; Bijad, M. Fabrication of a Nanostructure Voltammetric Sensor for Carmoisine Analysis as a Food Dye Additive Anal. Bioanal. Electrochem. 2018, 10.

41. Das, I.; Goel, N.; Agrawal, N.R.; Gupta, S.K. Growth patterns of dendrimers and electric potential oscillations during electropolymerization of pyrrole using mono-and mixed surfactants. J. Phys. Chem. B 2010, 114, 12888-12896, https://doi.org/10.1021/jp105183q.

42. Das, I.; Goel, N.; Gupta, S.K.; Agrawal, N.R. Electropolymerization of pyrrole: Dendrimers, nano-sized patterns and oscillations in potential in presence of aromatic and aliphatic surfactants. Journal of Electroanalytical Chemistry 2012, 670, 1-10, https://doi.org/10.1016/j.elechem.2012.01.023

43. Tkach, V.; Storoshchuk, N.; de Oliveira, S.; Luganska, O.; Gala, H.; Tchikuala, E.; Palamarek, K.; Nezveshchuk-Kohut, T.; Yagodynets, P. The Theoretical Evaluation of the Poly (3,4-dimethylpyrrole) Cathodic Electrodeposition, Assisted by Manganate Ions, Intercalated into a Conducting Polymer. Appl. J. Env. Eng. Sci. 2018, 4, 328-336.

44. Tkach, V.; Kushnir, M.; Storoshchuk, N.; de Oliveira, S.; Luganska, O.; Parchenko, V.; Bigdan, A.; Yagodynets', P. The Theoretical Description of Cathodic Pyrrole Electrodeposition, Assisted by a Dichromate of a Novel Triazolic Derivative. Rhazes 2018, 2.

45. Tkach, V.; Kushnir, M.; Ivanushko, Y.; de Oliveira, S.; Reis, L.; Yagodynets', P.; Kormosh, Z. The theoretical description for neotame electrochemical determination, assisted by vanadium oxyhydroxide composite with a squarainic dye. 2020, $6,109-115$.

46. Tkach, V.; Kushnir, M.; Storoshchuk, N.; Ivanushko, Y.; de Oliveira, S.; Yagodynets', P.; Kormosh, Z. The theoretical description for the confection of the novel thiourea- based active surface for cathodic conducting polymer deposition. Appl. J. Env. Eng. Sci. 2020, 6, 143-148.

47. Tkach, V.; Kushnir, M.; Ivanushko, Y.; de Oliveira, S.; Reis, L.; Yagodynets', P.; Kormosh, Z. The theoretical description for the electrochemical synthesis of a squaraine-dye doped conducting polymer. Appl. J. Env. Eng. Sci. 2020, 6, 51-56.

48. Tkach, V.V.; Storoshchuk, N.M.; Romaniv, L.V.; De Oliveira, S.C.; Luganska, O.V.; Gala, H.B.; Tchikuala, E.F.; Yagodynets, P.I. The theoretical evaluation of the poly(3,4-dimetylpyrrole) cathodic electrodeposition assisted by manganate ions. Vietnam Journal of Chemistry 2018, 56, 440-444, https://doi.org/10.1002/vjch.201800027.

49. Tkach, V.; Kushnir, M.; Ahafonova, O.; Mytchenok, M.; Bocharov, A.; Kovalchuk, P.; de Oliveira, S.; Yagodynets, P.; Kormosh, Z.; Reis, L.; Bredikhina, Y.; Ivanushko, Y.; Nazymok, Y. The theoretical description for the electrochemical determination of 4-4'-dihydroxyazobenzene, assisted by a composite of squaraine dye with cobalt (iii) oxyhydroxide in pair with cobalt (iv) oxide. Mediterranean Journal of Chemistry 2020, 10, 619-624, https://doi.org/10.13171/mjc10602007011465vvt. 